\title{
AESTHETIC OUTCOME AND THE NEED FOR REVISION OF UNILATERAL CLEFT LIP REPAIR AT KOMFO ANOKYE TEACHING HOSPITAL
}

\author{
A. A. OTI ${ }^{1}$, S. OBIRI-YEBOAH ${ }^{1}$ and P. DONKOR ${ }^{2}$ \\ ${ }^{1}$ Oral and Maxillofacial Surgery Unit, Komfo Anokye Teaching Hospital, Kumasi, Ghana \\ ${ }^{2}$ Oral and Maxillofacial Department, Kwame Nkrumah University of Science and Technology/Komfo \\ Anokye Teaching Hospital, Kumasi, Ghana
}

http://dx.doi.org/10.4314/gmj.v48i1.3

Corresponding author: Dr. Alex Acheampong Oti

Email: aotiacheampong@yahoo.com

Conflict of Interest: None declared

\section{SUMMARY}

Background: The Millard method of unilateral cleft lip repair has been associated with a short lip and a flattened nose on the cleft side. The aim of this study was to determine the need for revision surgery following repair of unilateral cleft lip repair at the Komfo Anokye Teaching Hospital

Method: Satisfaction with facial appearance (upper lip, nose and general facial appearance) was assessed quantitatively by means of a Visual Analogue Scale (VAS), where $0 \mathrm{~cm}$ indicates totally unsatisfied or "highly unattractive" and $10 \mathrm{~cm}$ indicates totally satisfied or "highly attractive". Three assessors - parents, surgeon and layperson - were purposively selected to score their level of satisfaction with repair of complete and incomplete unilateral cleft lip. The assessors also indicated the need for any revision.

Results: The total sample size was 120 , of which $40.0 \%$ were male and $60.0 \%$ were female. There were 79 cases of repaired complete unilateral cleft lip and 41 incomplete unilateral cleft lip. Average scores of satisfaction of parents were 6.6, 6.8 and 7.2 for nose, lip and general facial appearance (GFA) respectively. Satisfaction scores for surgeon were 6.1(nose), 6.0(lip) and 6.5(GFA), while those of the lay-assessor were 5.2(nose), 5.4 (lip) and 6.0(GFA). Concerning the need for revision, parents indicated $30.2 \%$ as needing revision, surgeon $33 \%$; and lay-assessor $40 \%$. Of the cases that needed revision, $33.3 \%$ were complete cleft lip and $0.1 \%$ were incomplete cleft lip.

Conclusion: Parents were more satisfied with unilateral cleft lip repair using the Millard procedure than either the surgeon or lay assessor. Those who needed revision were mostly children who presented with complete unilateral cleft lip.

\section{INTRODUCTION}

Cleft lip and palate are the most frequent congenital craniofacial deformities, with a mean prevalence of between 1:500 and 1:700 in Europe. ${ }^{1}$

The abnormalities vary greatly in terms of width of the cleft as well as other characteristics. Treatment modalities also differ with regard to timing of surgery and the technique of reconstruction. ${ }^{3}$

The facial region where this deformity occurs is a very conspicuous part of the body. Thus treatment of cleft lip and palate should provide both good aesthetic and functional (speech, occlusion) results. ${ }^{4,5}$ Successful surgical repair of the unilateral cleft lip is commonly defined as one that results in normal orbicularis oris ${ }^{6}$ function and a near perfect symmetry of the lip and nose. Unilateral cleft lip repair may, however, be associated with a number of complications that could affect the aesthetic outcome.

Evidence from various studies shows no comparative advantage of any of the lip repair techniques as far as the aesthetic outcome is concerned. However, the skill of the surgeon is considered most important. ${ }^{6,7}$ In our centre a closed repair of the nose is performed at the same time as the lip operation. This approach to lip repair is different from the approach used in most centres in Europe.

One of the major problems in the treatment of cleft lip and palate patients is that the definitive results of treatment are not assessable until nearly two decades after primary surgery. Because the patient's physical development and level of cooperation may vary, the final outcome cannot be predicted when the treatment starts. 
Ideally the final result should be assessed only when the patient is about 20 years old. ${ }^{2}$ In this study the minimum time for aesthetic assessment was six months after surgery by which time the scar would have matured.

Aesthetic assessment is difficult as it is mainly subjective with no acceptable standard for measuring aesthetics. $^{8,9}$

Unlike most studies on facial aesthetics after cleft lip surgery where assessment was done using photographs and questionnaire ${ }^{10,11}$, this study, used real patients.

In our sub-region, cleft lip deformity is associated with certain cultural beliefs especially as regards the aetiology and management. ${ }^{12,13}$ These beliefs sometimes cause delay in treatment and follow up which may also influence the final outcome of the repair. The Millard procedure, which is the preferred method of lip repair at the Komfo Anokye Teaching Hospital (KATH) because of its simplicity and the ability to modify it to suit a particular case, is often associated with a short lip and a flattened nose on the cleft side. ${ }^{14,15}$

The aim of this study is to evaluate the need for revision of unilateral cleft lip repair using Millard procedure at KATH in Ghana.

\section{METHODS}

This was a cross-sectional prospective study of aesthetic outcome among patients who had unilateral cleft lip repair. Patients who had unilateral lip repair surgery at KATH from 2006 to 2010 and consented were enrolled.

Three assessors, including mothers of selected children, a lay person (non-health person) and a senior cleft surgeon, assessed the repairs separately by indicating their level of satisfaction on a $10 \mathrm{~cm}$ Visual Analog Scale (VAS) where $0 \mathrm{~cm}$ indicates totally unsatisfied or "highly unattractive" and $10 \mathrm{~cm}$ indicates totally satisfied or "highly attractive".

Vernier calipers was used to measure from point zero to the marked point on the VAS and recorded as the level of satisfaction for that particular patient. A total satisfaction score for a particular index say the lip appearance was derived by summation of the individual scores for each client and dividing the result by the total number of children. Data were coded and entered into an excel spreadsheet and cleaned. Analysis was conducted using SPSS for windows V 170 (Chicago). Frequencies and descriptive statistics were calculated for all variables.

\section{RESULTS}

A total of 120 patients with a female to male ratio of $3: 2$ were assessed. Out of the number $66.0 \%$ had complete unilateral cleft lip while $34 \%$ had incomplete unilateral cleft lip. Table 1 shows the level of satisfaction with the general facial appearance of the patients after cleft repair as measured by the average visual analogue score.

Table 1 Level of satisfaction by raters.

\begin{tabular}{|l|l|l|l|}
\hline \multirow{2}{*}{ Rater } & \multicolumn{3}{|c|}{ Average level of satisfaction } \\
\cline { 2 - 4 } & Nose & Lip & GFA* \\
\hline Parent & 6.6 & 6.8 & 7.2 \\
\hline Surgeon & 6.1 & 6.0 & 6.5 \\
\hline Layperson & 5.2 & 5.4 & 6.0 \\
\hline
\end{tabular}

KEY: *GFA-General facial appearance

Regarding the need for revision surgery of the nose, Table 2 shows the ratings of parents, surgeon and lay assessors. For both the nose and lip parents, surgeon, and lay assessor indicated $30.2 \%, 33.5 \%$, and $36.3 \%$ respectively as requiring revision. More cases of complete cleft lip $(33.3 \%)$ required revisions than incomplete cleft lip (0.1\%).

Table 2 Revision request by raters

\begin{tabular}{|l|l|l|l|}
\hline \multirow{2}{*}{ Rater } & \multicolumn{2}{|c|}{$\begin{array}{c}\text { Location for revi- } \\
\text { sion }\end{array}$} & Total/\% \\
\cline { 2 - 3 } & Nose & Lip & \\
\hline Parent & 35 & 19 & $54(30.2)$ \\
\hline Surgeon & 40 & 20 & $60(33.5)$ \\
\hline Layperson & 40 & 25 & $65(36.3)$ \\
\hline
\end{tabular}

Overall parents were more satisfied with repairs and requested fewer revision operations, while the lay assessor was the least satisfied with the repairs and requested most re-operations.

\section{DISCUSSION}

The preferred method of repair of unilateral cleft lip at KATH is the Millard technique which is also the method of choice in several centres and in the West African sub-region. ${ }^{12-15}$ Unfortunately, this method is often complicated by a short lip and a flattened nose on the cleft side ${ }^{4}$.In this present study, parents tended to show higher levels of satisfaction than the surgeon and the lay assessor (Table 1). This could be due to the fact that parents suffer the greater impact of the social rejection associated with this deformity and are therefore encouraged when they see the least improvement in their children to make them acceptable in society. On the other hand lay assessors were least satisfied and probably reflected more truly the expectations of the general community with regard to aesthetics. 
In a study (using postoperative photographs) to evaluate the aesthetic outcome of cleft lip surgery by the public using the visual analogue scale, the average score for general appearance, was 7.55, the aesthetics of the mouth was 7.40 and the nose was $7.23 .^{4}$ This study had a similar trend of satisfaction with average scores of GFA as 6.6, lip was 6.1 and nose was 6.0.

The difference in the scores of this study and the earlier ones could be attributed to the different methods used, in particular the limitations of the photographic method in assessing lip and nasal appearance. ${ }^{16,17}$

These limitations include variability of the quality of the photography; the view; and the distance between camera and patient. Additionally a picture is not likely to give the same detail as when the real patient is examined as was done in this study.

The nose had more requests by assessors for revision than the lip in the present study (Table 2). However, the lay-assessor requested for more revisions of the nose than the others. This supports the empirical observation at KATH that, the nose had the least satisfactory outcome when the Millard technique was used to repair unilateral cleft lip..

Concerning the need for revision of the nose, more revisions were requested by the assessors for those with complete unilateral cleft lip than incomplete type. This is probably due to the fact that the more severe deformity seen in complete unilateral cleft lip requires greater skill to recreate the base and floor of the nose than is required for the incomplete type. The other important finding is that, surgeons tended to request for revision of the nose more often than the other assessors. There was also a higher demand for revision of the lip in patients with complete unilateral cleft lip and the lay-assessor was the one least satisfied with the appearance of the lip.

The need for secondary repair of the nose in this study confirms the finding by Ahuja ${ }^{18}$ that primary nasal correction in infants was not successful in restoring nasal shape and symmetry and those patients will usually require secondary nasal correction at a later age. This means that patients who have undergone primary repair of the lip and/or nose deformity will need secondary rhinoplasty regardless of the technique used for the primary repair.

\section{CONCLUSION}

It was observed from the study that between $30 \%-40 \%$ of patients with unilateral cleft lip treated at the Komfo Anokye Teaching Hospital required revision surgery of the lip or nose, based on assessments by parents, a sur- geon and a lay assessor.. Parents were more satisfied with the repair than either the surgeon or lay assessor. More cases of complete unilateral cleft lip were assessed to require revision than incomplete unilateral cleft lip.

\section{REFERENCES}

1. Emsen IM. Modification of the repair of a unilateral cleft lip. J Craniofac Surg. 2008;19(5):13301342.

2. Gundlach KK, Schmitz R, Maerker R, Bull HG. Late results following different methods of cleft lip repair. Cleft Palate J. 1982;19(3):167-171.

3. Onah I, Opara K, Olaitan P, Ogbonnaya I. Cleft lip and palate repair: the experience from two West African sub-regional centres ${ }^{2}$. Journal of Plastic, Reconstructive \& Aesthetic Surgery. 2008;61(8):879-882.

4. Jeffery SL, Boorman JG. Patient satisfaction with cleft lip and palate services in a regional centre. Br J Plast Surg. 2001;54(3):189-191.

5. Marcusson A, Paulin G, Ostrup L. Facial appearance in adults who had cleft lip and palate treated in childhood. Scand J Plast Reconstr Surg Hand Surg. 2002;36(1):16-23.

6. Lazarus DD, Hudson DA, van Zyl JE, Fleming AN, Fernandes D. Repair of unilateral cleft lip: a comparison of five techniques. Ann Plast Surg. 1998;41(6):587-594.

7. Lo L-J, Wong F-H, Mardini S, Chen Y-R, Noordhoff MS. Assessment of bilateral cleft lip nose deformity: a comparison of results as judged by cleft surgeons and laypersons. Plast. Reconstr. Surg. 2002;110(3):733-738; discussion 739-741.

8. Landsberger P, Proff P, Dietze S, et al. Evaluation of patient satisfaction after therapy of unilateral clefts of lip, alveolus and palate. J Craniomaxillofac Surg. 2006;34 Suppl 2:31-33.

9. He X, Shi B, Kamdar M, et al. Development of a method for rating nasal appearance after cleft lip repair. Journal of Plastic, Reconstructive \& Aesthetic Surgery. 2009;62(11):1437-1441.

10. Semb G, Brattström V, Mølsted K, et al. The Eurocleft study: intercenter study of treatment outcome in patients with complete cleft lip and palate. Part 4: relationship among treatment outcome, patient/parent satisfaction, and the burden of care. Cleft Palate Craniofac. J. 2005;42(1):8392.

11. Brusati R, Mannucci N, Biglioli F, Di Francesco A. Analysis on photographs of the growth of the cleft lip following a rotation-advancement flap repair: preliminary report. $J$ Craniomaxillofac Surg. 1996;24(3):140-144. 
12. Olasoji HO, Hassan A, Ligali TO. Challenges of cleft care in Africa. Afr $J$ Med Med Sci. 2009;38(4):303-310.

13. Orkar KS, Ugwu BT, Momoh JT. Cleft lip and palate: the Jos experience. East Afr Med J. 2002;79(10):510-513.

14. Donkor P, Plange-Rhule G, Amponsah EK. A prospective survey of patients with cleft lip and palate in Kumasi. West Afr J Med. 2007;26(1):1416.

15. Donkor P, Bankas DO, Agbenorku P, PlangeRhule G, Ansah SK. Cleft lip and palate surgery in Kumasi, Ghana: 2001-2005. J Craniofac Surg. 2007;18(6):1376-1379.
16. Morrant DG, Shaw WC. Use of standardized video recordings to assess cleft surgery outcome. Cleft Palate Craniofac. J. 1996;33(2):134-142.

17. Shaw WC, Asher-McDade C, Brattström V, et al. A six-center international study of treatment outcome in patients with clefts of the lip and palate: Part 1. Principles and study design. Cleft Palate Craniofac. J. 1992;29(5):393-397.

18. Ahuja RB. Primary definitive nasal correction in patients presenting for late unilateral cleft lip repair. Plast. Reconstr. Surg. 2002;110(1):17-24. 